Revista Herencia Vol. 26 (1 y 2), 111-126, 2013

Recibido 11-10-2013 Aprobado 16-11-2013

\title{
Páginas recuperadas
}

\section{VIAJE A COSTA RICA EN 1857 de Uladislao Durán}

"El Dr. Don Uladislao Durán de su país vino á éste como esas aves emigrantes que huyen del mal tiempo buscando abrigo; pero no para reposar un rato, no por un breve período, sino para terminar su itinerario, trasladándose con su nido, Ileno de los recuerdos, de los cariños y ensueños de la patria abandonada"... (Fragmento de oración fúnebre pronunciada por Juan N. Venero. La Gaceta, 10-11-1881).

Luis Armando Durán Segura. Bachiller y Licenciado en Antropología por la Universidad de Costa Rica. Magíster en Antropología Social y Magíste

en Estudios Culturales por

la Universidad de los Andes,

Colombia. luarduse@yahoo.es

\section{VIAJE A COSTA-RICA}

Mi querido amigo

En tu última que recibí al dejar á Grey-town, me encargas te haga una fiel y esacta descripcion de esta República: y aunque la tarea es dificil y complicada para mi, que carezco de la armonía del poeta, de la facundia del orador y del talento descriptivo, necesario al que se propone historiar, no vacilo en cumplir tus deseos, bien persuadido que tú llenarás los vacios que dejan mi mal cortada pluma y mi pobre injenio, con la tuya rica y amena y con tú imajinacion ardiente y creadora. 







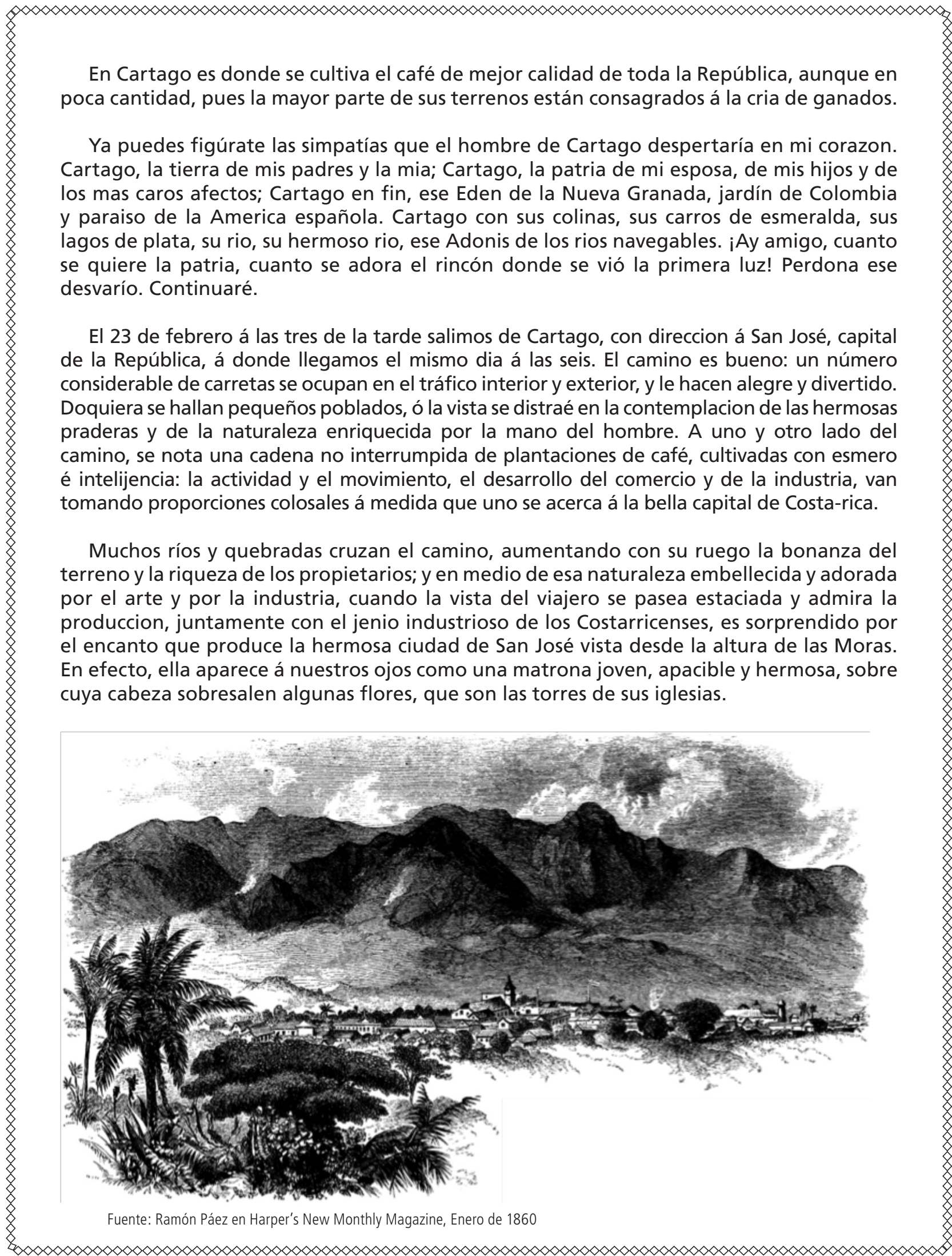




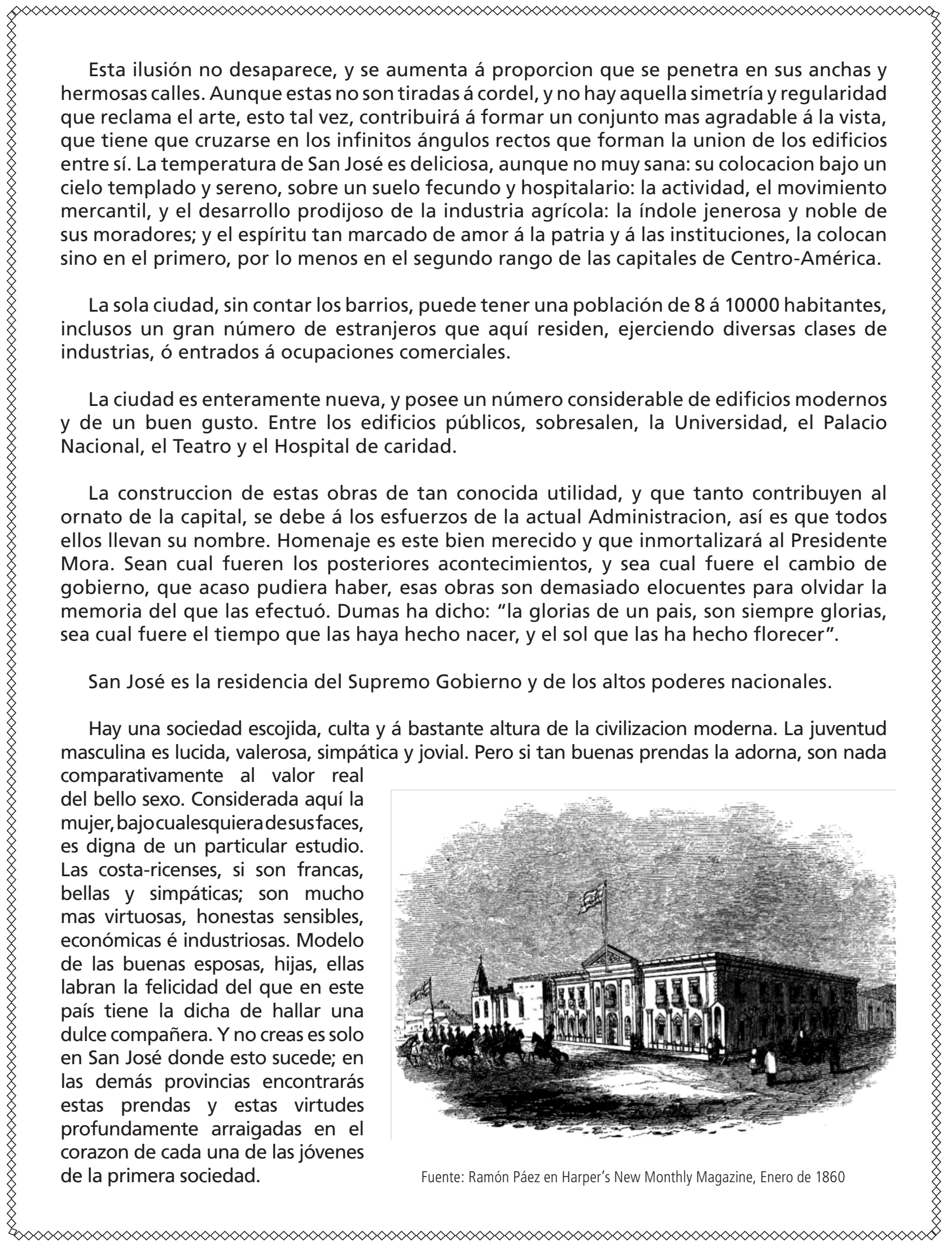




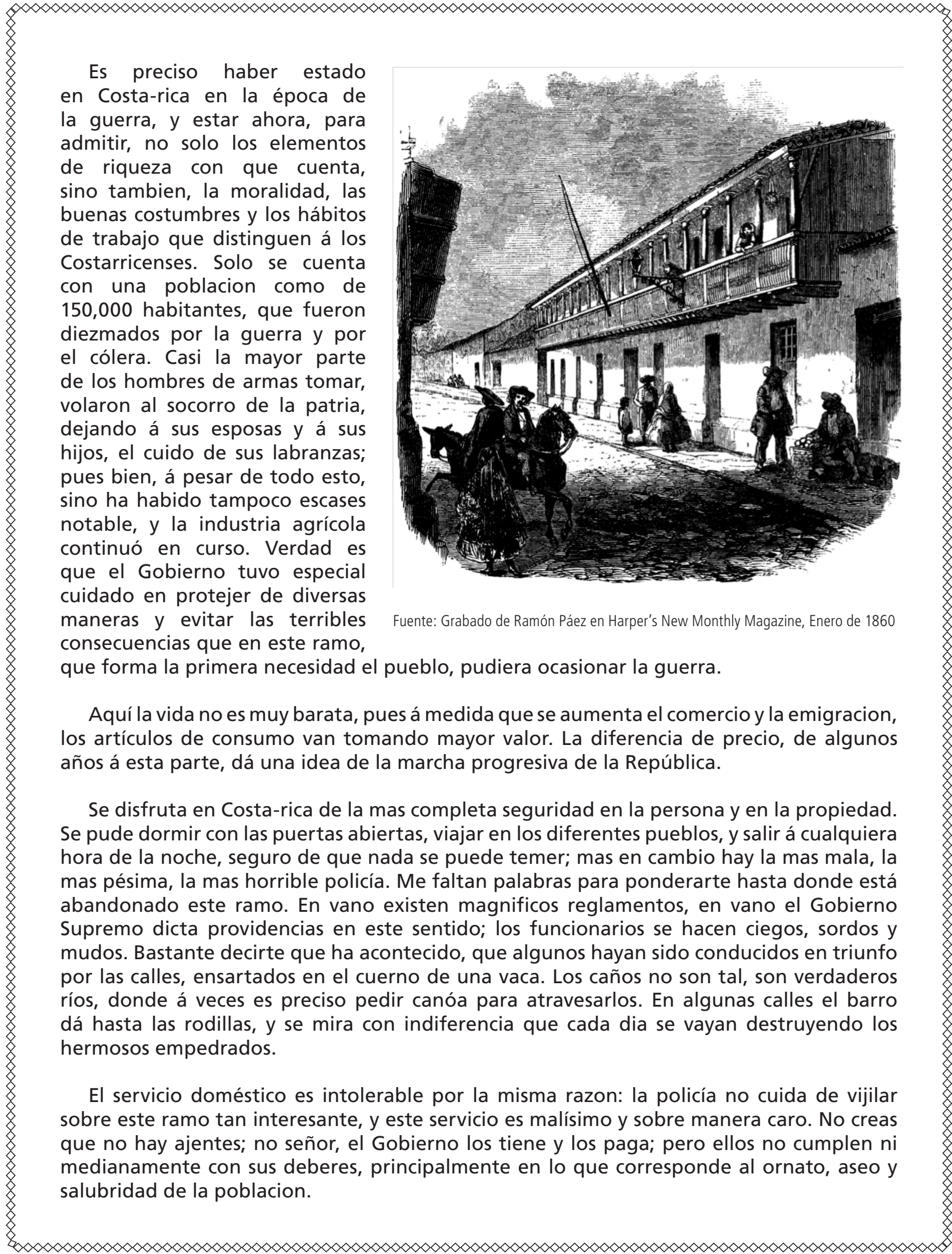




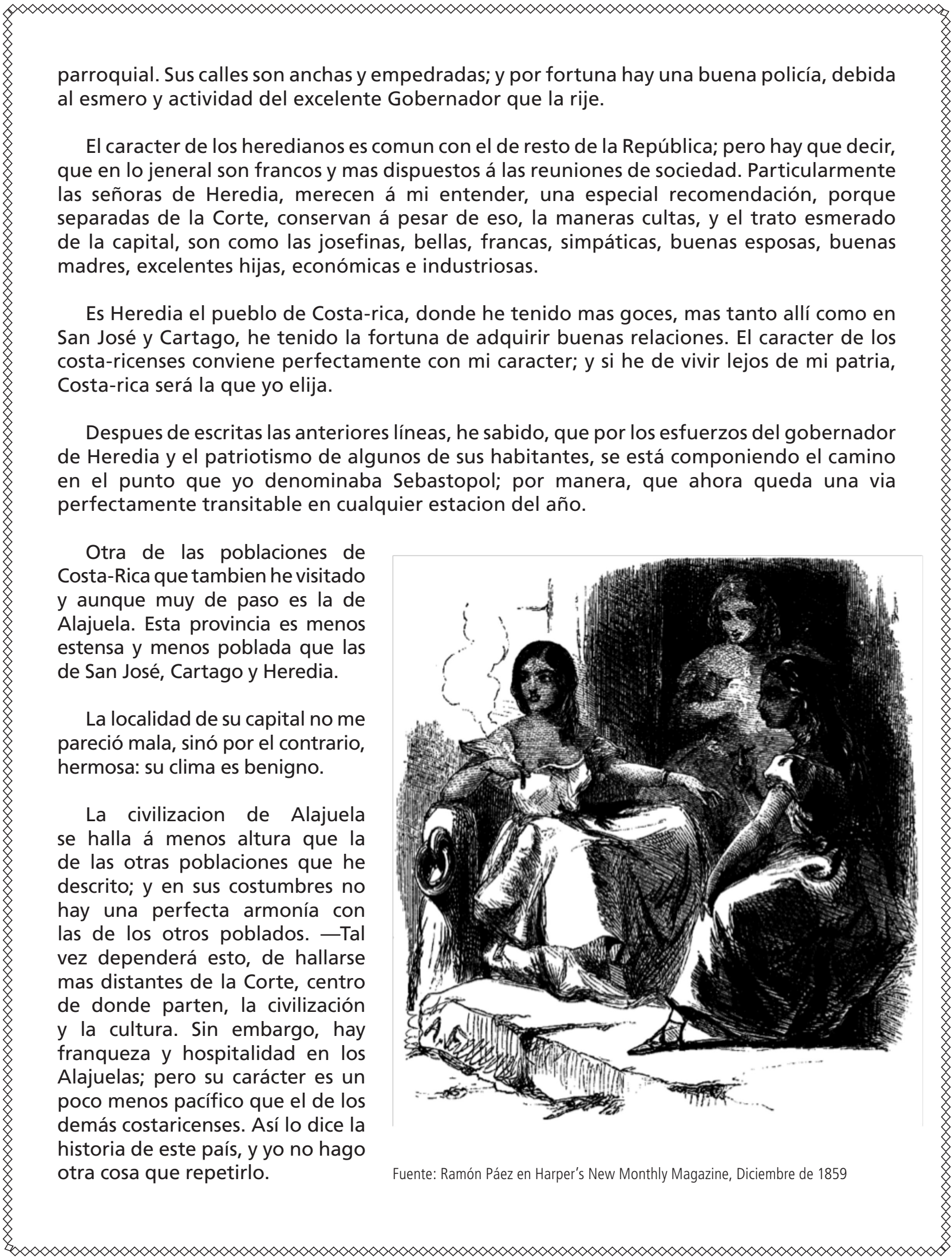




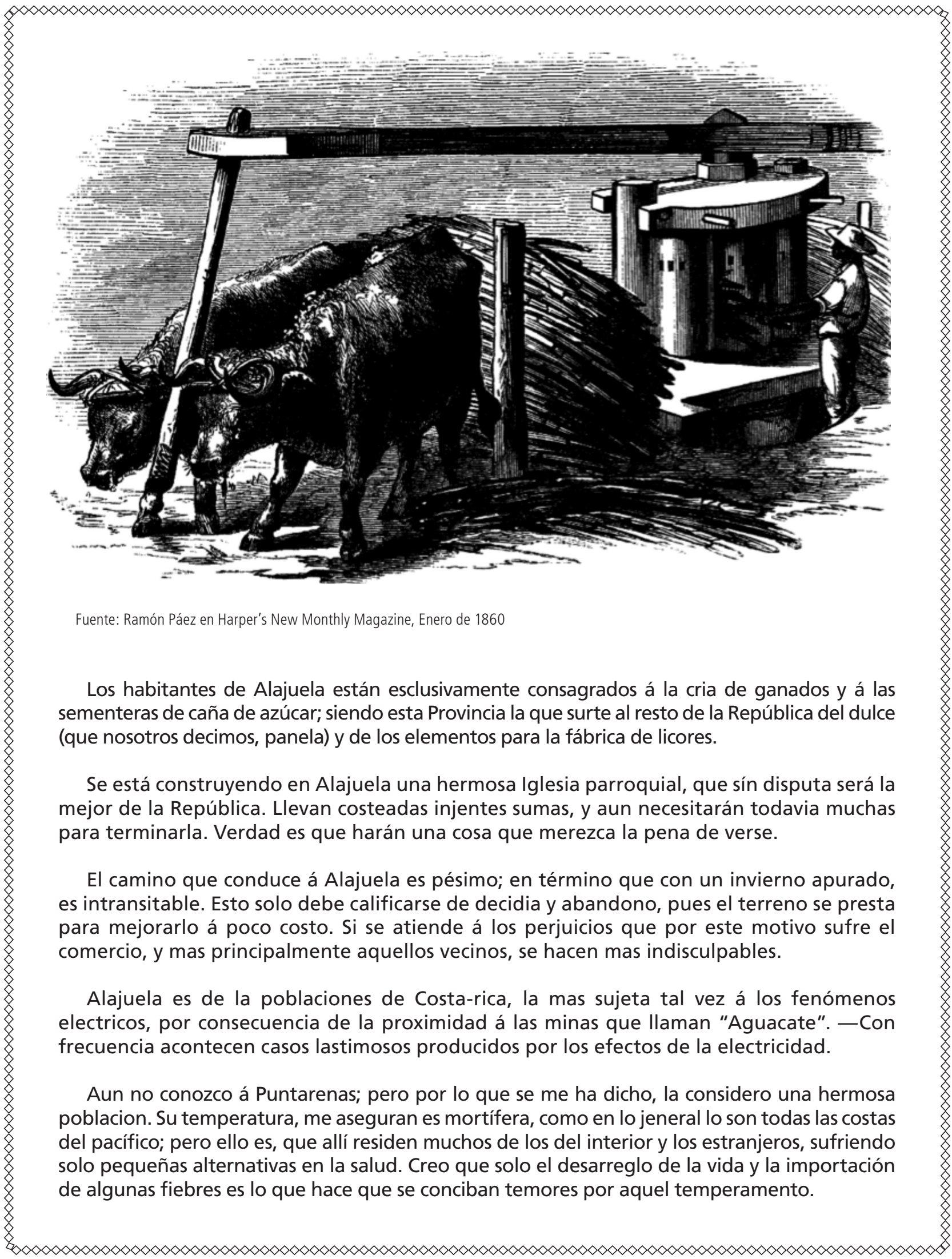




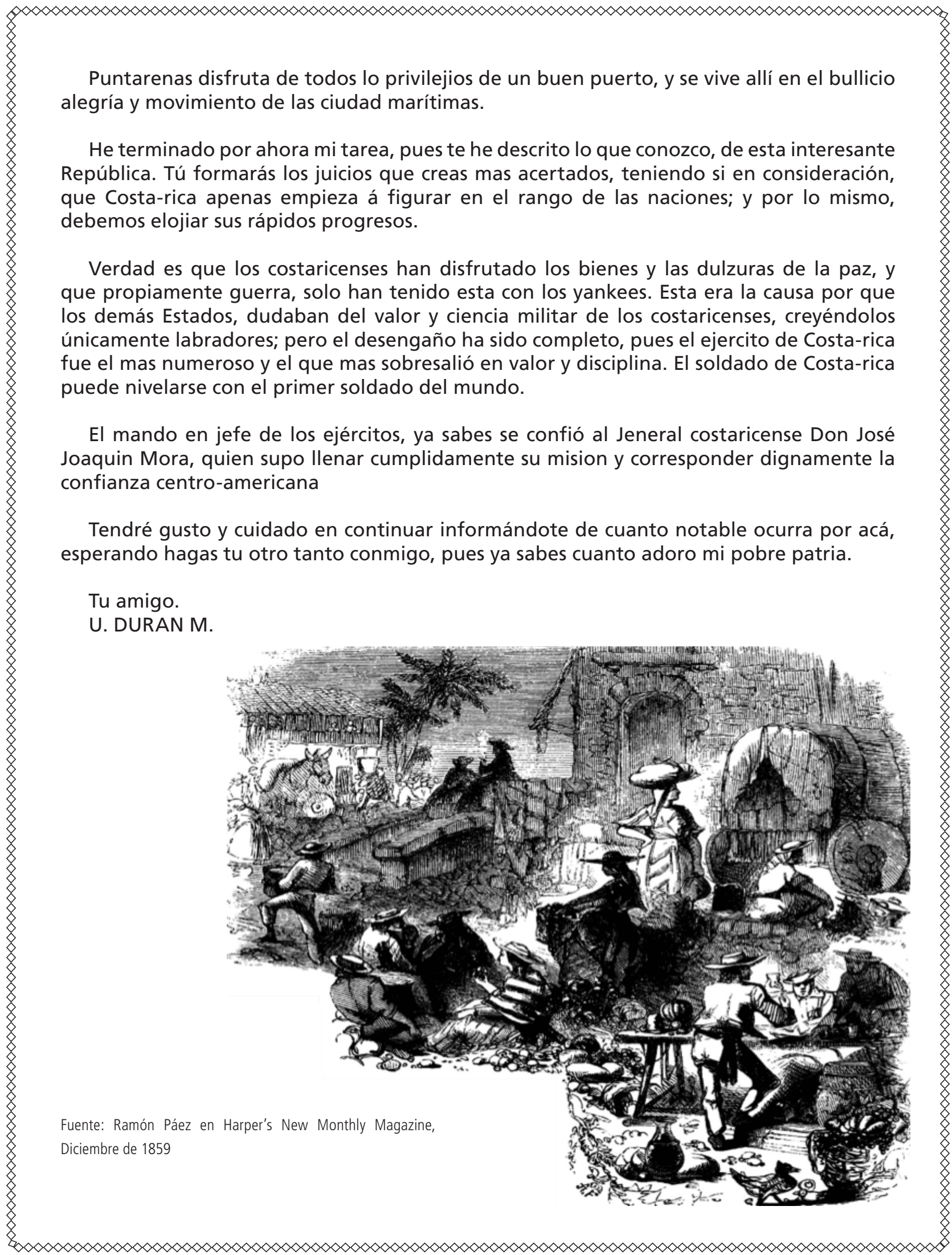




\section{Notas}

1. Uladislo Durán M. (Bogotá, 1809 - San José, 1881) fue un jurista colombiano que residió en Costa Rica durante 25 años. Ejerció en su natal Colombia, en El Salvador y en Guatemala. En nuestro país desempeñó múltiples cargos políticos y administrativos en el gobierno de Tomás Guardia Gutiérrez. Fungió además como director de la Imprenta Nacional y redactor del Diario Oficial. El relato que se reproduce fue publicado originalmente en cuatro tractos en el periódico Crónica de Costa Rica en sus números: No. 31 (22-07-1857) p. 3-4; No. 32 (25-07-1857) p. 4; No. 33 (29-07-1857) p. 3-4; No. 34 (01-08 1857) p. 4. Se acompaña el texto con una serie de grabados ilustrativos realizados por José Ramón Páez entre 1859 y 1860. 